DOI: 10.2478/achi-2020-0011

\title{
NOVEL POLY(VINYL ALCOHOL)-G- ACRYLAMIDE GRAFT MEMBRANES AS OXYGEN BARRIERS AND THEIR APPLICATION IN FRUITS AND VEGETABLE PACKAGING
}

\author{
M. B. Patil ${ }^{\text {a* }}$ S. B. Rajamani ${ }^{\text {a }}$ R. S. Gani ${ }^{\text {b }}$ \\ ${ }^{a}$ Bharat Ratna Prof. CNR Rao Research Centre, Basaveshwar Science \\ College, Bagalkot-587101, India \\ ${ }^{b}$ Department of Industrial Chemistry, Mangalore University, Mangalore- \\ 574199, India
}

\begin{abstract}
The membranes based on poly(vinyl alcohol) grafted with acryl amide have been synthesized by free radical polymerization. The membranes thus formed were characterized by Fourier transform infrared spectroscopy (FTIR) to study the chemical interactions. Membranes were prepared in two different thicknesses (40 and $60 \mu \mathrm{m}$ ) and used for measuring the oxygen permeability under varying feed pressures (maintaining the preferred gas pressure differential throughout the membrane) in the range from 1 to $40 \mathrm{~kg} / \mathrm{cm}^{2}$ pressure. Oxygen permeability of the membranes ranged from 0.0091 to 1.6165 Barrer for $40 \mu \mathrm{m}$ and 0.0305 to 0.1409 Barrer for $60 \mu \mathrm{m}$ thick membranes by increasing the feed pressures on the feed side. Except at $40 \mathrm{~kg} / \mathrm{cm}^{2}$ pressure, the observed oxygen permeability values are almost close to total permeability. Membranes of this study could be useful as oxygen barriers for applications in fruits and vegetable packaging industries.
\end{abstract}

Key Words: poly(vinyl alcohol); grafted membranes; gas separation; packaging material; Barrier

\section{Introduction}

Membrane-based gas separation (GS) has evolved as an important unit operation in chemical industries, competing successfully with several other conventional-type separation techniques, such as cryogenic

\footnotetext{
*Mallikarjunagouda Patil, e-mail: mallupatil04@gmail.com
} 
distillation, pressure-swing adsorption, and simple absorption. ${ }^{1,2}$ The last decade has witnessed an exponential increase in the development of novel polymeric membranes as effective, economic, and flexible tools in gasseparation problems. Commercial exploitation of polymeric membranes for air separation, recovery of hydrogen from nitrogen, carbon monoxide, and methane mixtures, and removal of carbon dioxide from natural gas have been widely reported. ${ }^{3,4}$ In such applications, high fluxes and excellent selectivities have relied mostly on glassy polymeric membranes that base separations on differences in gas sizes. However, this technology has focused on utilizing materials near the ambient temperature. The development of novel polymers offering important combinations of high selectivity, high permeability, good mechanical stability, and processability at ambient temperatures and pressures has been quite slow. ${ }^{5}$ In general, the flexible polymer films have favorable properties like low cost, good barrier properties against moisture and gases, heat sealable to prevent leakage of contents, possess both wet and dry strengths, easy to handle, and add little weight to the final product. Thus, they fit closely to the shape of the food, thereby wasting little space during storage and distribution. In food packaging applications, oxygen barrier properties of the polymers are important, since many food materials require the specific atmospheric conditions to sustain their freshness and quality during the storage. Hence, food materials are increasingly being packed in a protective atmosphere with a specific mixture of gases, thereby ensuring optimum quality and safety of the product. However, to ensure a constant gas composition inside the packaging film, the polymer should have certain specific oxygen barrier properties. $^{6}$ 
Transparent and flexible gas barrier films are key components in food packaging. In most cases, food processors are mainly served by low density PE (LDPE) and linear low-density PE (LLDPE). ${ }^{7}$ The main problem of polyethylene is its high oxygen permeability. Having a barrier capacity is crucial for plastics films used in the food packaging which favors the preservation of nutritional and organoleptic product qualities. For this purpose, it is necessary to prevent food product losses (aroma, $\mathrm{CO}_{2}$ loss, and loss modified atmosphere) as well as the penetration of external gas (oxygen and steam) through plastics. ${ }^{8-10}$ Different technologies are developed so as to supply chemical element barrier to clear films, as PE films, used for packaging applications. The main technologies area unit the following: (1) Coating with high barrier materials, generally inorganic oxide layers (e.g., $\mathrm{SiOx}$ or $\mathrm{Al}_{2} \mathrm{O}_{3}$ ), these films show optical transparency and very low gas transmission rates at low thickness $(<100 \mathrm{~nm})[9,10]$ but they tend to form imperfections during deposition, they present low substrate adhesion and when they are flexed are prone to crack. ${ }^{11}$ (2) Multilayer films area unit shaped from monolayers; the one that is within may be a skinny layer of a barrier material (e.g.EVOH, polyamide or aluminium) and the outer layers of structural polymers (e.g. PE, PP or PET). In spite of their efficacy, a high adherence between the materials is necessary. In addition, another problem is their recyclability due the use of different types of polymers and adhesives in the same film. ${ }^{12}$ Current trends regarding plastic packaging are focused on developing thinner structures with high barrier properties, diminishing raw material. (3) A new alternative to common technologies is the use of clay nanocomposites that improve plastics properties, increasing not only the barrier and mechanical properties, but 
also heat resistance. ${ }^{13}$ Getting a complete exfoliation of nanoclays (nanoclay layers are completely separated, with high surface area) is necessary in order to obtain proper results using nanocomposites. Moreover, a high affinity between compound Associate in Nursingd clay sheets and also the exfoliation area unit required for an adequate dispersion of clays into the polymer, ${ }^{14-15}$ achieving these properties. Plastic films as a packaging material have several advantages over the conventional food packaging. The material is very less proven to contamination and pilferage. By using plastic as packaging material the shelf life of the food product becomes longer. The materials will gives the very attractive texture and is leveraged for the nice branding purposes. The plastic films are very light weight in nature and very easy to print on its surface. Additionally the films are very good barrier properties and are recyclable and reusable. The different packaging materials available in the market are high Density Polyethylene, Low Density Polyethylene, Polypropylene, Polyethylene terephthalate (PET or PETE), Polycarbonate, Polyethylene naphthalate, Polystyrene etc. ${ }^{16}$

However, since the contact of food stuff with polymeric films may alter the performance. It is very important parameter to study the barrier characteristics of the packaging materials under realistic conditions. For instance, the absorption of ambient vapor or gases materials may causes and plasticization of plastic, resulting in mechanical strength ${ }^{17}$ and also there are chances of contaminations like oxygen may cause ripening or rotten of the food materials. The aim of the present investigation is to lighten the more information of the permeability behavior of the polymer films that are used as packaging materials for food industry. 


\section{Materials and Methods}

\section{Chemicals}

PVA (MW 125,000) and Acryl amide were purchased from s.d. Fine Chemicals, Mumbai, India. Benzyol peroxide (BPO) was purchased from E. Merk (India), Mumbai, India. All other chemicals were of reagent grade samples and were used without further purification. Double distilled water was used throughout the research.

\section{Synthesis of graft copolymer}

The synthesis of grafting reaction to obtain copolymer was done in aqueous media. The two different polymeric membranes with same concentration and same synthesis conditions but different membrane thickness were prepared. The ratio of PVA/Acryl amide and benzyol peroxide as initiator was used. PVA was dissolved in water at $80{ }^{\circ} \mathrm{C}$, the 6 wt. \% slurry was obtained then known quantity of acryl amide and initiator $(0.4 \mathrm{wt}$. $\%$ to comonomer) were introduced under constant stirring in the reaction vessel. Further, the temperature was raised and maintained at $90{ }^{\circ} \mathrm{C}$ for $5 \mathrm{Hrs}$. The obtained products were precipitated in acetone, filtered and vacuum dried at $70{ }^{\circ} \mathrm{C}$. The two different membranes with thickness i.e. 40 and $60 \mu \mathrm{m}$ were prepared.

\section{Permeability Measurements}

Single gas permeabilities for $\mathrm{O}_{2}$ were evaluated using a gas permeameter. The Permeameter consists of a stainless steel permeation cell which separates upstream (feed side) and downstream (permeate side). A pressure transducer is connected to the downstream side to measure the pressure change with time in the permeate side. This cell exposes a 
membrane area of $13.302 \mathrm{~cm}^{2}$ to the gas. The membrane separation follows the solution diffusion modem and it involves sorption at the top side of the membrane and diffusion across the barrier and finally desorption at another side of the membrane. The schematic diagram and its mechanism are shown in figure 1.

The constant-volume variable pressure method was used to measure the permeation of the pure gas. The pressure increase with time was plotted from the raw data. The gas permeability is calculated based on the following equation:

$$
P=\frac{V l}{A} \frac{T_{0}}{P_{f} P_{0} T}\left[\left(\frac{d p}{d t}\right)_{s s}-\left(\frac{d p}{d t}\right)_{\text {leak }}\right]
$$

Where:

- $\quad P$ is the permeability of the gas through the membrane (barrer), (1 Barrer $=10^{-10} \mathrm{~cm} 3$ (STP) $\mathrm{cm} \mathrm{cm}^{-2} \mathrm{~s}^{-1} \mathrm{cmHg}^{-1}$ ).

- $\quad V$ is the permeate volume $\left(\mathrm{cm}^{3}\right)$.

- $\quad l$ is the thickness of the membrane layer $(\mathrm{cm})$.

- $A$ is the effective area of the membrane $\left(\mathrm{cm}^{2}\right)$.

The ideal selectivity $\alpha_{\mathrm{A} / \mathrm{B}}$ of gas pairs, $\mathrm{A}$ and $\mathrm{B}$, was calculated. It is defined as the ratio of their permeably:

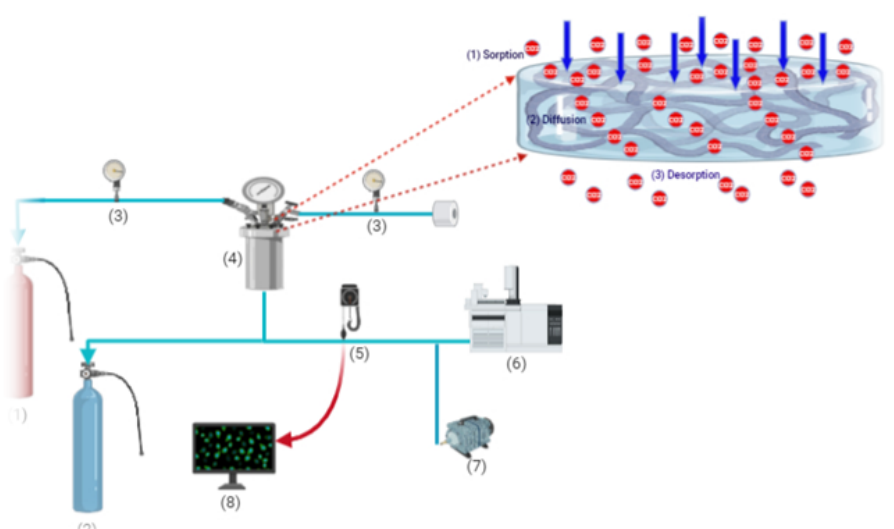

Figure 1. Schematics of the gas separation unit: (1) And (2) Gas Cylinders (3) Pressure Gauge (4) Membrane gas permeate unit (5) Pressure transmitters (6) Gas Chromatography (7) Vacuu pump and (8) Output unit. 


\section{Membrane characterization}

Fourier transform infrared spectroscopy (FTIR) spectra of the plain PVA and PVA-g-AAm membranes were taken in the range between 4000 and $400 \mathrm{~cm}^{-1}$ to confirm the formation of grafting reaction of PVA with acrylamide using Nicolet-740, PerkinElmer-283B FTIR spectrometer (Milawankee, WI). Membrane samples were grounded well with $\mathrm{KBr}$ and pellets were formed by pressing under the hydraulic pressure of $400-450 \mathrm{~kg} / \mathrm{cm}^{2}$. FTIR spectral curves are displayed in Figure 2.

\section{Results and Discussion}

\section{FTIR Studies}

IR spectra of PVA-grafted with acrylamide, unmodified PVA and acrylamide, are presented. In the spectrum of PVA, the broad peak at about $3420 \mathrm{~cm}^{-1}$ is assigned to $-\mathrm{OH}$ and $\mathrm{C}-\mathrm{OH}$ stretching. The peak at $2925 \mathrm{~cm}^{-1}$ is attributed to asymmetric $-\mathrm{CH}_{2}-$ group stretching vibration. The peak at $1417 \mathrm{~cm}^{-1}$ is due to $-\mathrm{OH}$ bending vibration of the hydroxyl group. The peaks at 1090 and $810 \mathrm{~cm}^{-1}$ are ascribed to $\mathrm{C}-\mathrm{O}$ stretching and $\mathrm{C}-\mathrm{C}$ stretching vibration, respectively. For poly(acrylic acid-coacrylamide), the peak at $3436 \mathrm{~cm}^{-1}$ is attributed to the $-\mathrm{NH}$ stretching vibration of the acrylamide unit, which overlapped with the -OH groups of acrylate units. The specific absorption bands at $1650 \mathrm{~cm}^{-1}$ corresponding to $v \mathrm{C}=\mathrm{O}$ group (amide band 1) and $1600 \mathrm{~cm}^{-1}$ represents the $v \mathrm{NH}$ group (amide band 2) are found in the synthesized copolymer as well. This peak revels that PVA grafing reaction with Acrylamide took place. The graph was plotted in figure 2 . 


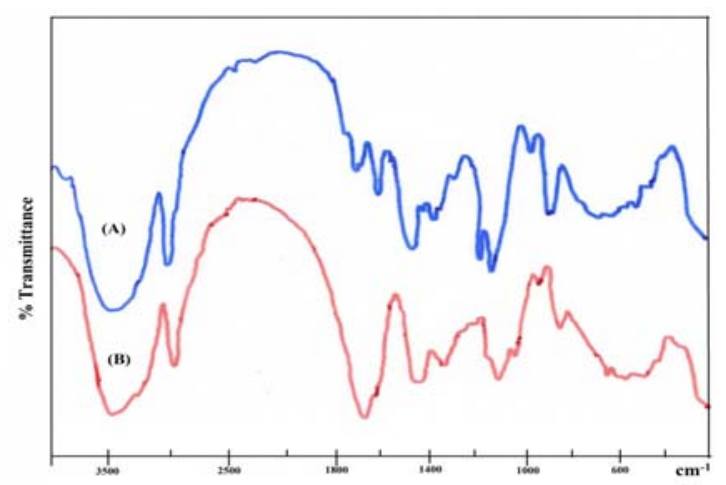

Figure 2. IR spectra of grafted copolymer PVA/acrylamide and PVA.

Gas Permeability Studies

The prepared membranes were assessed for the oxygen gas permeability measurement. Pure gas permeability was measured for $\mathrm{O}_{2}$ with the prepared PVA-g-AAm membranes (40 and $60 \mu \mathrm{m}$ thickness). The permeability values for the tested gases are tabulated in Table 1.

Table 1. Effect of Feed Pressure on Oxygen Permeability at $25^{\circ} \mathrm{C}$.

\begin{tabular}{ccc}
\hline $\begin{array}{c}\text { Pressure Applied } \\
\left(\mathbf{k g} / \mathbf{c m}^{\mathbf{2}}\right)\end{array}$ & \multicolumn{2}{c}{ Permeability K (Barrer) } \\
\cline { 2 - 3 } & PVA-g-AAm-40 & PVA-g-AAm-60 \\
\hline 1 & 0.0072 & N/A \\
5 & 0.0098 & N/A \\
10 & 0.014 & N/A \\
20 & 0.0341 & 0.0307 \\
30 & 0.0444 & 0.0411 \\
40 & 0.153 & 0.176 \\
\hline
\end{tabular}

$\mathrm{N} / \mathrm{A}=$ data not available.

1 Barrer $=10^{-10} \mathrm{~cm}^{3}(\mathrm{STP}) \mathrm{cm} \mathrm{cm}^{-2} \mathrm{~s}^{-1} \mathrm{cmHg}^{-1}$ PVA-g-AAm-40 and PVA-g-AAm-60 are membranes of thickness of 40 and $60 \mu \mathrm{m}$ respectively. 


\section{Membrane performance}

Membranes were assessed for oxygen permeability by varying the feed pressures (maintaining the desired pressure differential across the membrane) and thickness of the membranes. The permeability $(\mathrm{K})$ values are given in Table I. In case of PVA-g-AAm-40 membrane, the pressure was increased from 1 to $40 \mathrm{~kg} / \mathrm{cm}^{2}$. At $1 \mathrm{~kg} / \mathrm{cm}^{2}$ pressure, the permeability was 0.0072 Barrer, which has increased to 0.0098, 0.014, 0.0341, 0.0444 and 0.153 respectively at $1,5,10,20,30$ and $40 \mathrm{~kg} / \mathrm{cm}^{2}$ pressures. Whereas the PVA-g-AAm-60 membrane shown zero permeability from the pressure 1 to $10 \mathrm{~kg} / \mathrm{cm}^{2}$ and $0.0307,0.0411,0.176$ for the corresponding pressure i.e. 20,30 and $40 \mathrm{~kg} / \mathrm{cm}^{2}$. Even at high pressures the prepared membranes have shown a very poor permeability towards oxygen. Hence we may conclude that these are the better candidates for the packaging of Fruits and vegetables since oxygen is the one of the component which will spoils the shelf life of the same.

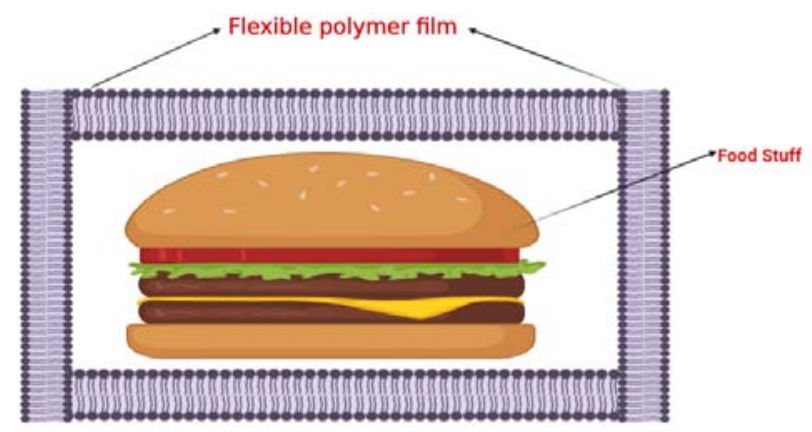

Figure 2: Illustration of the food packed in the flexible polymeric film.

The schematic packed food by polymer film was illustrated in the figure 2. As the COVID-19 outbreak has spread and its humanitarian collision has increased, industries that help provide for essential needs, such as getting food and required supplies safely to consumers, are increasingly 
affected. With food packaging being the packaging industry's largest area of activity, is greatly affected. It is necessary to develop the antiviral food packaging materials.

\section{Conclusions}

The effort to study the oxygen barrier property was shown very efficiently by preparing the grafted copolymers. The PVA-g-AAm membranes clearly demonstrated the oxygen barrier properties. There is a wide range of high barrier films available, each offering unique benefits for various types of food products. The highly flexible poly vinyl alcohol (PVOH) barrier film and the same was grafted with acrylamide, for instance, is ideal for fruits and vegetable packaging. These membranes can be used as a substrate or as independent packaging material.

\section{Acknowledgements}

Authors are greatful to the B. V. V. Sangha, Bagalkot for providing research facilities and Sri. Ashok M. Sajjan (Bewoor), Chairman, College Governing Council, Basaveshwar Science College, Bagalkot for his continuous support towards our research work.

\section{References}

1. Patil, M. B.; Amshumali, M. K. Sweetening of Natural gas through hollow silica nanoparticles embedded Nanocomposite Hydroxy ethyl cellulose Membrane. Mat. Sci. Res. India 2018, 15, 256-262.

2. Hamidreza Sanaeepur, H.; Ebadi A. Amooghin; Bandehali, S.; Moghadassi, A.; Matsuura, T.; Bruggen, B. Polyimides in membrane gas separation: Monomer's molecular design and structural engineering. Prog. Polym. Sci. 2019, 91, 80-125.

3. Qiao, Z.; Zhao,, S.; Sheng, M.; Wang, J.; Wang, S.; Wang, Z.; Zhong, C.; Guiver, M. D. Metal-induced ordered microporous polymers for 
fabricating large-area gas separation membranes. Nature Mater. 2019, $18,163-168$.

4. Qiao, Z.; Chai, S.; Nelson, K; Bi, Z.; Chen, J.; Shannon M. Mahurin, Xiang Zhu \& Sheng Dai Polymeric molecular sieve membranes via in situ cross-linking of non-porous polymer membrane templates. Nat. Commun. 2014, 5, 3705.

5. Bernardo, P.; Drioli, E.; Golemme, G. Membrane gas separation: a review/state of the art. Ind. Eng. Chem. Res. 2009, 48, 4638-4663.

6. Rodenas, T.; Luz, I.; Prieto, G.; Seoane, B.; Miro, H.; Corma, A.; Kapteijn, F.; Xamena, Francesc X. Labrés I.; Gascon, J. Metal-organic framework nanosheets in polymer composite materials for gas separation. Nature Mater. 2015, 14, 48-55.

7. Yu, J.; Ruengkajorn, K.; Crivoi, D.-G.; Chen C.; Buffet, Jean-Charles; O'Hare, D. High gas barrier coating using non-toxic nanosheet dispersions for flexible food packaging film. Nat. Commun. 2019, 10, 2398.

8. Rovera, C.; Ghaani' M.; Farris, S. Nano-inspired oxygen barrier coatings for food packaging applications: An overview. Trends Food Sci \& Tech, $2020,97$.

9. Merritt S. M. J.; Wemyss, A. M.; Farris, S.; Patole, S.; Patias, G.; Haddleton, D. M.; Shollock, B.; Wan, C. Gas Barrier Polymer Nanocomposite Films Prepared by Graphene Oxide Encapsulated Polystyrene Microparticles, ACS Appl. Polym. Mater. 2020, 2, 725-731.

10. Wang, K.; Miao, C.; Liu, Y.; Cai, L.; Jones, W.; Fan, J.; Li,D.; Feng, J. Vacancy enriched ultrathin TiMgAl-layered double hydroxide/graphene oxides composites as highly efficient visible-light catalysts for $\mathrm{CO}_{2}$ reduction. Appl. Cat. B: Environmental. 2020, 270, 118878.

11. Yildirim, S.; Röcker, B.; Pettersen, M. K.; Nygaard, J. N.; Ayhan, Z.; Rutkaite, R.; Radusin, T.; Suminska, P,; Marcos, B. Active Packaging Applications for Food, 2018, 17, 165-200.

12. McKeen, L. W. Introduction to the Mechanical, Thermal, and Permeation Properties of Plastics and Elastomer Films, Film Properties of Plastics and Elastomers (Fourth Edition), 2017, Plastics Design Library, William Andrew Publishers. 
13. Yu, J.; Ruengkajorn, K.; Crivoi, D.-G.; Chen C.; Buffet, Jean-Charles; O'Hare, D. High gas barrier coating using non-toxic nanosheet dispersions for flexible food packaging film. Nat. Commun. 2019, 10, 2398.

14. Ding, F.; Liu, J.; Zeng, S.; Xia, Y.; Kacie M. W.; Nieh, Mu-Ping; Sun, L. Biomimetic nanocoatings with exceptional mechanical, barrier and flame-retardant properties from large-scale one-step coassembly. Sci. Adv. 2017, 3, e1701212.

15. Yu, J.; Wang, Q.; O'Hare, D.; Sun, L. Preparation of two dimensional layered double hydroxide nanosheets and their applications. Chem. Soc. Rev. 2017, 46, 5950-5974.

16. https://www.cosmofilms.com/blog/uses-and-types-of-plastic-films-forfood-packaging/, Accessed on 22/04/2020.

17. Siracusa, V. Food Packaging Permeability Behaviour: A Report. Int. J. Polym. Sci. 2012, 2012, 1-11. 